\title{
Stroke Prevention - Medical and Lifestyle Measures
}

\author{
Hakan Sarikaya $^{a} \quad$ Jose Ferro $^{b}$ Marcel Arnold ${ }^{a}$

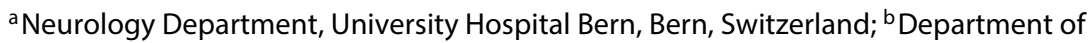 \\ Neurosciences (Neurology), Hospital de Santa Maria, University of Lisbon, Lisbon, Portugal
}

\section{Key Words}

Cerebrovascular disease - Hypertension - Ischemic stroke -

Risk factors for stroke $\cdot$ Stroke $\cdot$ Prevention

\begin{abstract}
Background: According to the World Health Organization, stroke is the 'incoming epidemic of the 21 st century'. In light of recent data suggesting that $85 \%$ of all strokes may be preventable, strategies for prevention are moving to the forefront in stroke management. Summary: This review discusses the risk factors and provides evidence on the effective medical interventions and lifestyle modifications for optimal stroke prevention. Key Messages: Stroke risk can be substantially reduced using the medical measures that have been proven in many randomized trials, in combination with effective lifestyle modifications. The global modification of health and lifestyle is more beneficial than the treatment of individual risk factors. Clinical Implications: Hypertension is the most important modifiable risk factor for stroke. Efficacious reduction of blood pressure is essential for stroke prevention, even more so than the choice of antihypertensive drugs. Indications for the use of antihypertensive drugs depend on blood pressure values and vascular risk profile; thus, treatment should be initiated earlier in patients with diabe-
\end{abstract}

tes mellitus or in those with a high vascular risk profile. Treatment of dyslipidemia with statins, anticoagulation therapy in atrial fibrillation, and carotid endarterectomy in symptomatic high-grade carotid stenosis are also effective for stroke prevention. Lifestyle factors that have been proven to reduce stroke risk include reducing salt, eliminating smoking, performing regular physical activity, and maintaining a normal body weight.

(c) 2015 S. Karger AG, Basel

\section{Introduction}

Stroke is one of the most common causes of death and is the main cause of persistent and acquired disability in adults worldwide. Considering demographic changes, a further increase in stroke rates is expected. Moreover, stroke is expected to increasingly affect younger patients. The World Health Organization refers to stroke as the incoming epidemic of the 21 st century. Therefore, currently, strategies for stroke prevention are of prime importance, particularly with regard to the recent studies suggesting that $85 \%$ of all strokes may be preventable [1]. Lifestyle modification is of particular interest for stroke prevention, as the incidence of stroke has decreased by up

\section{KARGER 125}

(c) 2015 S. Karger AG, Base

0014-3022/15/0734-0150\$39.50/0
Hakan Sarikaya, MD

Department of Neurology

University Hospital of Bern, Inselspital

CH-3010 Bern (Switzerland)

E-Mail hakan.sarikaya@insel.ch 
Table 1. Evidence for recommendations on the treatment and lifestyle factors related to stroke

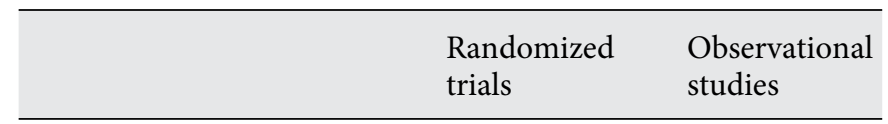

Arterial hypertension

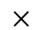

Diabetes mellitus

Dyslipidemia

Antithrombotics

Atrial fibrillation

Carotid stenosis

Vitamin supplementation

Dietary recommendations

Smoking

Physical activity

Alcohol

Overweight

to $42 \%$ in developed countries within the last 30 years, whereas an increase by more than $100 \%$ has been reported in developing countries [2]. This observation indicates the important role of lifestyle and diet; the prevalence of risk factors such as smoking, hyperlipidemia, or high blood pressure has decreased considerably, thereby increasing awareness among the populations of high-income countries. However, in low-income countries, industrialization has led to unfavorable food and lifestyle changes [2]. This review aims to discuss effective lifestyle modifications and medical interventions for optimal stroke prevention. An overview of the evidence for the recommendations is shown in table 1.

\section{Medical Measures}

\section{Arterial Hypertension}

Hypertension is the most important and modifiable risk factor for stroke. Uncontrolled hypertension is also a main cause of cognitive deficits and dementia. A reduction of systolic blood pressure (SBP) by $2 \mathrm{~mm} \mathrm{Hg}$ was associated with stroke reduction by $25 \%$, while reduction in diastolic blood pressure (DBP) led to stroke reduction by $50 \%$ [3]. The relationship between blood pressure and stroke risk is linear and continuous as the reduction of borderline hypertension (SBP 130-140 mm Hg and DBP $85-89 \mathrm{~mm} \mathrm{Hg}$ ) was also associated with risk reduction of stroke. Treatment of isolated SBP in elderly patients is also preventive: reduction of SBP $>160 \mathrm{~mm} \mathrm{Hg}$ to $145 \mathrm{~mm}$ $\mathrm{Hg}$ in patients aged $>80$ years was associated with stroke reduction by $30 \%$ within 2 years [4].

Stroke Prevention - Medical and Lifestyle Measures
Efficacious reduction of blood pressure is much more important and essential for stroke prevention than the choice of antihypertensive drugs. The selection of drug class should be made based on comorbidities. Some studies and meta-analyses suggest a beneficial trend in favor of calcium antagonists and angiotensin-converting enzyme blockers [5], whereas beta blockers in hypertensive patients without heart disease seem to be less protective for stroke prevention. Recent studies indicate that a high variability in blood pressure is associated with a higher stroke risk, which again supports treatment with calcium antagonists [6]. Furthermore, patients with metabolic risk factors who are treated with thiazide diuretics or beta blockers seem to have a higher risk for the new onset of diabetes mellitus [7].

Indications for the use of antihypertensive drugs depend on blood pressure values and the vascular risk profile; thus, treatment should be initiated earlier in patients with diabetes mellitus or in those with a high vascular risk profile. In patients with a low risk profile and borderline blood pressure values, non-pharmaceutical treatment options should be used (e.g., low-salt diet, physical activity, or weight reduction). Antihypertensive drug treatment is recommended for all patients with blood pressure $>140 / 90 \mathrm{~mm} \mathrm{Hg}$, whereas the treatment goal in high-risk patients should be ideally blood pressure levels of $<130 / 80$ $\mathrm{mm} \mathrm{Hg}$.

\section{Dyslipidemia and Statins}

The association between stroke and hypercholesterinemia is less clear, although it is an established risk factor for myocardial infarction. Many studies indicate an increased risk of ischemic stroke with higher serum cholesterol levels ( $>7 \mathrm{mmol} / \mathrm{l})$, whereas lower cholesterol levels in patients with hypertension (SBP >145 mm $\mathrm{Hg}$ ) tend to be associated with hemorrhagic stroke. Hypercholesterinemia is clearly related to carotid atherosclerosis [8], whereas HDL-cholesterol is inversely associated with the risk of ischemic stroke. Statins have been shown to prevent stroke markedly in patients with coronary heart disease, diabetes mellitus, or carotid stenosis, whereas this was not the case for the use of fibrates. The action of statins is assumed to be mediated through pleiotropic effects (anti-inflammatory, immunomodulatory, plaque stabilizer, vasodilatation) [9]. While the use of statins is clearly indicated for secondary prevention after ischemic stroke due to artery atheromatosis, it is controversial whether statins may reduce stroke risk in the healthy population without vascular disease [10]. The absolute risk reduction for 
healthy people seems to be rather low ( $0.2 \%$ per year), and so the use of statins in general cannot be recommended.

\section{Diabetes Mellitus}

Patients with diabetes mellitus have a higher risk of vascular events. According to a prospective observational study, patients with type 2 diabetes suffered more frequently from stroke than from myocardial infarction [11]. Diabetes promotes cerebral microangiopathy and causes lacunar type strokes. Current data indicate that metformin may be beneficial for stroke prevention in diabetes [12]. Intense control of hyperglycemia rather reduces microvascular complications, whereas the effect on macrovascular complications such as stroke is not clear [13]. Moreover, intense control of present vascular risk factors such as hypertension or dyslipidemia has been shown to efficiently reduce the risk of cardiovascular events in diabetic patients [14]. In addition, the use of statins has been shown to significantly reduce stroke risk (by $21 \%$ for each $1 \mathrm{mmol} / \mathrm{l}$ decrease in LDL-cholesterol).

\section{Carotid Stenosis}

The prevalence of asymptomatic carotid stenosis $>50 \%$ increases with age and in patients with coronary heart disease, smoking, and diabetes mellitus. On the other hand, patients with carotid stenosis have a 4-fold higher risk of myocardial infarction than stroke [15]. While endarterectomy of symptomatic carotid stenosis is a proven and beneficial treatment for secondary stroke prevention, its value for asymptomatic stenosis remains controversial. Randomized trials from the nineties have suggested a benefit for surgery in asymptomatic carotid stenosis of $\geq 60 \%$ to $\geq 70 \%$ (relative risk reduction by $50 \%$ ), provided the perioperative complication risk is less than $3 \%$ and patients have a life expectancy $\geq 5$ years $[16,17]$. Considering the absolute risk reduction of $1 \%$ per year, however, the treatment effect was rather low. Moreover, recent studies suggested a stroke risk of $<1 \%$ per year for patients with asymptomatic carotid stenosis and treated with intensive medical therapy, which was primarily attributed to regular use of antihypertensive drugs and statins and lifestyle modification. This new observation questions the value of surgery in asymptomatic patients [18]. Therefore, current randomized studies such as SPACE-2 are investigating the absolute benefit of asymptomatic carotid stenosis. Percutaneous intervention by stenting is considered a justifiable alternative to surgery in symptomatic carotid stenosis, especially in patients younger than 70 years. Considering asymptomatic stenosis, the current body of evidence is insufficient for recommending stents as standard therapy.

\section{Intracranial Stenosis}

Current data recommend an aggressive medical treatment of intracranial stenosis as angioplasty and stenting in symptomatic patients was clearly associated with a higher risk of adverse outcomes [19]. Anticoagulation caused higher rates of intracranial hemorrhages than antiplatelet agents and was not superior in preventing a secondary ischemic stroke [20].

\section{Atrial Fibrillation}

The prevalence of atrial fibrillation increases with age (1\% in 60-year-old patients, $18 \%$ in patients aged $>85$ years). It is the leading cause of stroke in the elderly and is associated with large infarcts and high mortality rates. A regular pulse palpation in patients aged $>65$ years and electrocardiography in the case of arrhythmic heart rate is recommended by cardiology societies to detect atrial fibrillation and prevent ischemic stroke [21]. The decision for anticoagulation in non-valvular atrial fibrillation is made according to the $\mathrm{CHA}_{2} \mathrm{DS}_{2}$ VASc score [21]. As compared to the former $\mathrm{CHADS}_{2^{-}}$ score, the new score places more emphasis on age, gender, and vascular co-morbidities of patients and recommends anticoagulation at a score $\geq 1$ points, except for women without any other risk factors. Furthermore, the specificity in defining low-risk patients has also increased; thus, no more aspirin is recommended for this group (score $=0$ points). In general, aspirin is less effective for stroke prevention in atrial fibrillation. Anticoagulation reduces the stroke risk by $70 \%$ in atrial fibrillation and the benefit of treatment in older patients with atrial fibrillation by far outweighs the bleeding risk, which can be estimated by HAS-BLED Score $[22,23]$. However, studies indicate an underuse of anticoagulants due to physicians' perception on the risk of major bleeding as excessively high, because of the presence of clinical risk factors such as falls. It has been calculated that the risk of subdural hematoma that happens as a result of falling is so small that persons with an average stroke risk of $5 \%$ per year must fall approximately 300 times in a year for the risks of anticoagulation to outweigh its benefits [24]. As compared to vitamin K-antagonists, the new anticoagulants (thrombin inhibitor, factor Xa-antagonist) have the main advantages of easier usage and a higher safety profile, particularly a lower risk of intracranial hemorrhage. On the other hand, 
the new oral anticoagulants may have the following disadvantages as compared with vitamin K-antagonists: short duration of action leading to increased stroke risk in case of poor compliance, lack of monitoring and antidote in case of emergent surgery or bleeding, and higher costs.

\section{Patent Foramen Ovale}

The best treatment for patent foramen ovale (PFO) in cryptogenic stroke is still under debate. Closure of PFO with Amplatzer devices seems reasonable in younger patients without vascular risk factors, whereas PFO in older stroke patients with vascular comorbidities is probably incidental and thus do not necessarily need a closure [25, 26]. The best medical treatment for PFO (antiplatelet vs. anticoagulant) is the subject of ongoing studies.

\section{Sleep Disordered Breathing}

Sleep disordered breathing (SDB) has been increasingly recognized as an independent risk factor for stroke [27, $28]$. SDB can be the cause and the consequence of stroke $[29,30]$. The high frequency $(50-70 \%)$ of SDB in stroke patients, often in the form of obstructive sleep apnea (OSA), justifies the routine implementation of screening tools such as respiratory polygraph or apnea check. In severe OSA, treatment with continuous positive airway pressure (CPAP) may reduce the cardiovascular morbidity and mortality, whereas the evidence for efficient stroke prevention is still limited $[31,32]$.

\section{Antithrombotics}

For primary stroke prevention, acetylsalicylic acid (aspirin) has been the most investigated antithrombotic drug. The Women's Health Study reported a stroke reduction by $17 \%$ in healthy women taking $100 \mathrm{mg}$ aspirin every 2 days as compared to placebo; however, the difference was statistically non significant [33]. In the Physicians' Health Study, no stroke prevention was observed in men treated with aspirin [34]. A recent meta-analysis including 95,000 participants found no association between aspirin and primary stroke prevention, in either women or men, whereas the rates of gastrointestinal bleeding were significantly increased in the aspirin arm [35]. Current data do not support a general use of aspirin for stroke prevention in the healthy population or in patients with diabetes mellitus [36]. On the other hand, antithrombotics including aspirin, clopidrogel, and dipyridamol are clearly indicated for secondary stroke prevention in patients with ischemic stroke (relative risk reduction by $20-25 \%)$.

Stroke Prevention - Medical and Lifestyle Measures

\section{Lifestyle Modification}

\section{Salt}

The average salt intake in most Western countries is close to $10 \mathrm{~g}$ a day (and much higher in many Eastern European and Asian countries), whereas international recommendations suggest that average population salt intake should be less than 5-6 g per day [37]. Intake of higher salt amounts is associated with higher risk for ischemic and hemorrhagic stroke [37]. About $20 \%$ of all intracerebral hemorrhages are assumed to result from adding salt to food [38]. Moreover, reduction of dietary salt intake by half a teaspoon was associated with a reduction of cardiovascular events by $20 \%$ [39]. The risk is assumed to result from increased blood pressure, leading to fibrosis in the arteries, kidneys, and heart [40]. Reduction of dietary salt intake by a teaspoon (equal to 5-6 g salt) has been shown to reduce systolic and diastolic blood pressure by 7 and $4 \mathrm{~mm} \mathrm{Hg}$, respectively, in hypertensive patients, whereas blood pressure reduction in patients with resistant hypertension was much higher (systolic by 23 $\mathrm{mm} \mathrm{Hg}$ and diastolic by $9 \mathrm{~mm} \mathrm{Hg}$, respectively) [41, 42]. Of note, many people consume prepared foods, which contain a lot of salt and this makes control of salt intake difficult.

\section{Smoking}

Cigarette smoking is an independent risk factor for stroke and potentiates the effect of other risk factors such as hypertension or hormone replacement therapy. The mechanism is due to reduced endogenous fibrinolysis and increased thrombocyte activity. Recent studies also suggest an association between passive smoking and stroke. Stroke risk was reduced by $50 \%$ one year after quitting smoking, and was comparable to that of nonsmokers 5 years later.

\section{Physical Activity}

Regular physical activity decreases stroke risk by 25$30 \%$ through favorable effects on other vascular risk factors such as hypertension, hyperlipidemia, and overweight. The dose-effect relation is controversial, however; thus, it is not clear whether maximal physical activity leads also to maximal stroke reduction.

\section{Overweight}

Each unit increase in body mass index (BMI) has been suggested to increase stroke risk by $5 \%$. However, stroke mortality is also increased in underweight patients. Markers of abdominal obesity such as waist-to-hip ratio or 
waist circumference are reported to correlate better with stroke risk. While obesity is an established risk factor for stroke occurrence, recent studies report decreased mortality risk in obese stroke patients as compared to normal weight patients ('obesity paradox'). To date, however, randomized trials on risk modification by weight reduction are lacking.

\section{Alcohol}

The association between alcohol consumption and stroke risk is J-shaped: while slight to moderate alcohol intake ( $\leq 2$ drinks per day for men and $\leq 1$ drink per day for women, respectively) may reduce stroke risk by $30 \%$, higher consumption significantly increases the risk of stroke.

\section{Vitamins}

There is robust evidence from many randomized trials that supplementation with vitamins $\mathrm{A}, \mathrm{C}, \mathrm{E}$, or beta-carotene does not reduce the risk of stroke. Moreover, increased mortality rates have been observed for regular substitution with beta-carotene and vitamins $\mathrm{A}$ and $\mathrm{E}$. Although hyperhomocysteinemia is a known risk factor for stroke and serum levels of homocysteine can be lowered by treatment with folic acid and vitamin B12, randomized trials did not prove stroke prevention by regular folate supplementation [43]. Vitamin B3 (niacin) was reported to reduce stroke risk in former studies, while statins were not used regularly. Supplementation with niacin increased HDL-cholesterol levels in patients treated with statins, but did not reduce stroke rates [44].

\section{Potassium}

Several observational studies and a meta-analysis have indicated that a higher potassium intake is associated with a reduction of stroke risk by $21 \%$ (relative risk 0.79 , 95\% CI 0.60-0.90) [45]. The effect seems to be dose-dependent: every increase in potassium intake by $1 \mathrm{~g}$ per day resulted in a reduction of stroke risk by $11 \%$ [46]. The mechanism is probably partially mediated by the reduction of blood pressure [47].

\section{Calcium}

Randomized trials have shown that calcium supplementation of $>500 \mathrm{mg}$ per day was associated with a significant risk for myocardial infarction and a trend toward an increase in stroke [48]. A meta-analysis of 3 placebocontrolled trials including $>20,000$ patients showed similar results for the combined supplementation of calcium and vitamin D [49].
Fats

Current studies indicate no significant association between stroke risk and the amount of fat intake, fat origin (animal vs. vegetable), and types of fats (saturated vs. polyunsaturated) [50,51]. Consumption of industrially produced trans fats or saturated fatty acids, however, have been shown to increase the risk of coronary heart disease $[52,53]$. Although marine-derived, omega-3 polyunsaturated fatty acids (from oily fish such as salmon or herring) have been reported to significantly reduce the risk of cardiovascular deaths in several randomized trials, no significant effect on stroke prevention has been demonstrated to date $[54,55]$. On the other hand, the consumption of plant-derived omega-3 polyunsaturated fatty acids (from vegetable oils such as walnut, flaxseed, or soybean) has been reported to decrease stroke risk according to an observational study, although this needs to be confirmed in randomized trials [56].

\section{Protein and Carbohydrates}

The amount of protein intake and protein type (animal vs. vegetable) does not seem to be a risk factor for stroke [57]. Consumption of foods and liquids with added sugars and high dietary glycemic indices increases the risk for overweight, diabetes mellitus, and coronary heart disease [58]. Increased stroke mortality was reported among the Japanese people with high carbohydrate intake [59].

\section{Foods and Beverages}

Regular fish consumption was associated with a reduced stroke risk as reported by several observational studies [60], whereas daily meat consumption is shown to increase the risk of stroke [61]. Increased intake of fruits and vegetables ( $>5$ servings per day) significantly reduce the stroke risk, whereas vegetable intake alone did not prevent strokes $[1,62]$. The mechanism is not clearly known, although reduction of blood pressure is thought to play an important role. A recent study reported that high plasma levels of lyocopene (e.g., found in tomatoes) were associated with a reduced risk of stroke by $50 \%$ [63]. Moderate consumption (3-4 cups) of coffee or tea has been shown to reduce stroke risk as compared with no consumption $[64,65]$. The mechanism may be due to their antioxidative effects and improved endothelial function. Chocolate consumption was also associated with lower rate of stroke and cardiovascular disease, possibly mediated by the antiinflammatory and antithrombotic effects of cocoa [66]. Finally, the Mediterranean diet has recently been reported to reduce stroke risk [67]. 
Global Lifestyle Modification

Global modification of lifestyle has been shown to be more beneficial than the treatment of single risk factors. Patients fulfilling all 5 criteria of low-risk lifestyle (no smoking, regular physical activity $\geq 30 \mathrm{~min}$ per day, healthy nutrition, moderate alcohol consumption, BMI $<25 \mathrm{~kg} / \mathrm{m}^{2}$ ) had a reduced stroke risk by $80 \%$ as compared to patients fulfilling none of these criteria [68].

\section{Conclusions}

In summary, stroke risk can be substantially reduced using the medical measures proven in many randomized trials. Arterial hypertension is by far the most important risk factor for stroke, whereas treatment of dyslipidemia with statins will further reduce the stroke risk. Anticoagulation in atrial fibrillation and carotid endarterectomy in symptomatic high-grade carotid stenosis are also very efficient in stroke prevention, whereas the general use of aspirin, statins, or vitamins cannot be recommended for healthy people. Observational data strongly indicate that lifestyle modifications such as healthy diet, cessation of smoking and alcohol overuse, regular physical activity and achievement of normal body weight are beneficial for stroke prevention. However, one should consider that most lifestyle recommendations rely on case-control and epidemiological studies, which may be hampered by bias. The main challenge will be to educate and convince the population on the benefits that can be expected from healthy lifestyle and nutrition, as smoking and some dietary habits may rather be considered addictions. Therefore, structured therapy programs may be warranted in many situations.

\section{Acknowledgment}

The authors thank Turgut Tatlisumak (MD, $\mathrm{PhD}$ ) for his valuable comments on the manuscript.

\section{References}

1 O'Donnell MJ, Xavier D, Liu L, Zhang H, Chin SL, Rao-Melacini P, Rangarajan S, Islam S, Pais $\mathrm{P}, \mathrm{McQueen} \mathrm{MJ}$, et al: Risk factors for ischaemic and intracerebral haemorrhagic stroke in 22 countries (the INTERSTROKE study): a case-control study. Lancet 2010;376:112-123.

- Hankey GJ: Nutrition and the risk of stroke. Lancet Neurol 2012;11:66-81.

-3 Sokol SI, Kapoor JR, Foody JM: Blood pressure reduction in the primary and secondary prevention of stroke. Curr Vasc Pharmacol 2006;4:155-160.

4 Beckett NS, Peters R, Fletcher AE, Staessen JA, Liu L, Dumitrascu D, Stoyanovsky V, Antikainen RL, Nikitin Y, Anderson C, et al: Treatment of hypertension in patients 80 years of age or older. N Engl J Med 2008;358: 1887-1898.

5 Psaty BM, Lumley T, Furberg CD, Schellenbaum G, Pahor M, Alderman MH, Weiss NS: Health outcomes associated with various antihypertensive therapies used as first-line agents: a network meta-analysis. JAMA 2003; 289:2534-2544.

6 Rothwell PM: Limitations of the usual bloodpressure hypothesis and importance of variability, instability, and episodic hypertension. Lancet 2010;375:938-948.

7 Elliott WJ, Meyer PM: Incident diabetes in clinical trials of antihypertensive drugs: a network meta-analysis. Lancet 2007;369:201207.

8 Wilson PW, Hoeg JM, D’Agostino RB, Silbershatz H, Belanger AM, Poehlmann H, O'Leary
D, Wolf PA: Cumulative effects of high cholesterol levels, high blood pressure, and cigarette smoking on carotid stenosis. N Engl J Med 1997;337:516-522.

9 Endres M: Statins and stroke. J Cereb Blood Flow Metab 2005;25:1093-1110.

10 Ridker PM, Danielson E, Fonseca FA, Genest J, Gotto AM Jr, Kastelein JJ, Koenig W, Libby P, Lorenzatti AJ, MacFadyen JG, et al: Rosuvastatin to prevent vascular events in men and women with elevated C-reactive protein. $\mathrm{N}$ Engl J Med 2008;359:2195-2207.

-11 Martin S, Schramm W, Schneider B, Neeser $\mathrm{K}$, Weber C, Lodwig V, Heinemann L, Scherbaum WA, Kolb H: Epidemiology of complications and total treatment costs from diagnosis of Type 2 diabetes in Germany (ROSSO 4). Exp Clin Endocrinol Diabetes 2007;115:495-501.

12 Effect of intensive blood-glucose control with metformin on complications in overweight patients with type 2 diabetes (UKPDS 34). UK Prospective Diabetes Study (UKPDS) Group. Lancet 1998;352:854-865.

13 Gerstein HC, Miller ME, Genuth S, IsmailBeigi F, Buse JB, Goff DC Jr, Probstfield JL, Cushman WC, Ginsberg HN, Bigger JT, et al: Long-term effects of intensive glucose lowering on cardiovascular outcomes. N Engl J Med 2011;364:818-828.

14 Gaede P, Vedel P, Larsen N, Jensen GV, Parving $\mathrm{HH}$, Pedersen O: Multifactorial intervention and cardiovascular disease in patients with type 2 diabetes. N Engl J Med 2003;348:383-393.
15 Goessens BM, Visseren FL, Kappelle LJ, Algra A, van der Graaf Y: Asymptomatic carotid artery stenosis and the risk of new vascular events in patients with manifest arterial disease: the SMART study. Stroke 2007;38:14701475.

16 Endarterectomy for asymptomatic carotid artery stenosis. Executive Committee for the Asymptomatic Carotid Atherosclerosis Study. JAMA 1995;273:1421-1428.

17 Halliday A, Mansfield A, Marro J, Peto C, Peto R, Potter J, Thomas D: Prevention of disabling and fatal strokes by successful carotid endarterectomy in patients without recent neurological symptoms: randomised controlled trial. Lancet 2004;363:14911502.

18 Abbott AL: Medical (nonsurgical) intervention alone is now best for prevention of stroke associated with asymptomatic severe carotid stenosis: results of a systematic review and analysis. Stroke 2009;40:e573-e583.

19 Chimowitz MI, Lynn MJ, Derdeyn CP, Turan TN, Fiorella D, Lane BF, Janis LS, Lutsep HL, Barnwell SL, Waters MF, et al: Stenting versus aggressive medical therapy for intracranial arterial stenosis. N Engl J Med 2011;365:9931003.

20 Chimowitz MI, Lynn MJ, Howlett-Smith H, Stern BJ, Hertzberg VS, Frankel MR, Levine SR, Chaturvedi S, Kasner SE, Benesch CG, et al: Comparison of warfarin and aspirin for symptomatic intracranial arterial stenosis. N Engl J Med 2005;352:1305-1316. 
21 Camm AJ, Kirchhof P, Lip GY, Schotten U, 33 Ridker PM, Cook NR, Lee IM, Gordon D, GaSavelieva I, Ernst S, Van Gelder IC, Al-Attar N, Hindricks G, Prendergast B, et al: Guidelines for the management of atrial fibrillation: the Task Force for the Management of Atrial Fibrillation of the European Society of Cardiology (ESC). Eur Heart J 2010;31: 2369-2429.

22 Pisters R, Lane DA, Nieuwlaat R, de Vos CB, Crijns HJ, Lip GY: A novel user-friendly score (HAS-BLED) to assess 1-year risk of major bleeding in patients with atrial fibrillation: the Euro Heart Survey. Chest 2010;138:10931100.

23 Hart RG, Benavente O, McBride R, Pearce LA: Antithrombotic therapy to prevent stroke in patients with atrial fibrillation: a metaanalysis. Ann Intern Med 1999;131:492-501.

24 Man-Son-Hing M, Nichol G, Lau A, Laupacis A: Choosing antithrombotic therapy for elderly patients with atrial fibrillation who are at risk for falls. Arch Intern Med 1999;159: 677-685.

25 Stortecky S, da Costa BR, Mattle HP, Carroll J, Hornung M, Sievert H, Trelle S, Windecker S, Meier B, Juni P: Percutaneous closure of patent foramen ovale in patients with cryptogenic embolism: a network meta-analysis. Eur Heart J 2014;pii:ehu292, Epub ahead of print.

26 Kent DM, Ruthazer R, Weimar C, Mas JL, Serena J, Homma S, Di Angelantonio E, Di Tullio MR, Lutz JS, Elkind MS, et al: An index to identify stroke-related vs incidental patent foramen ovale in cryptogenic stroke. Neurology 2013;81:619-625.

-27 Yaggi HK, Concato J, Kernan WN, Lichtman $\mathrm{JH}$, Brass LM, Mohsenin V: Obstructive sleep apnea as a risk factor for stroke and death. $\mathrm{N}$ Engl J Med 2005;353:2034-2041.

-28 Bradley TD, Floras JS: Obstructive sleep apnoea and its cardiovascular consequences. Lancet 2009;373:82-93.

29 Bassetti CL, Milanova M, Gugger M: Sleepdisordered breathing and acute ischemic stroke: diagnosis, risk factors, treatment, evolution, and long-term clinical outcome. Stroke 2006;37:967-972.

-30 Hermann DM, Bassetti CL: Sleep-related breathing and sleep-wake disturbances in ischemic stroke. Neurology 2009;73:13131322.

-31 Campos-Rodriguez F, Martinez-Garcia MA, de la Cruz-Moron I, Almeida-Gonzalez C, Catalan-Serra P, Montserrat JM: Cardiovascular mortality in women with obstructive sleep apnea with or without continuous positive airway pressure treatment: a cohort study. Ann Intern Med 2012;156:115-122.

- 32 Barbe F, Duran-Cantolla J, Sanchez-de-laTorre M, Martinez-Alonso M, Carmona C, Barcelo A, Chiner E, Masa JF, Gonzalez M, Marin JM, et al: Effect of continuous positive airway pressure on the incidence of hypertension and cardiovascular events in nonsleepy patients with obstructive sleep apnea: a randomized controlled trial. JAMA 2012;307: 2161-2168. ziano JM, Manson JE, Hennekens CH, Buring JE: A randomized trial of low-dose aspirin in the primary prevention of cardiovascular disease in women. N Engl J Med 2005;352:12931304.

34 Final report on the aspirin component of the ongoing Physicians' Health Study. Steering Committee of the Physicians' Health Study Research Group. N Engl J Med 1989;321:129135.

35 Baigent C, Blackwell L, Collins R, Emberson J, Godwin J, Peto R, Buring J, Hennekens C, Kearney P, Meade T, et al: Aspirin in the primary and secondary prevention of vascular disease: collaborative meta-analysis of individual participant data from randomised trials. Lancet 2009;373:1849-1860.

36 De Berardis G, Sacco M, Strippoli GF, Pellegrini F, Graziano G, Tognoni G, Nicolucci A: Aspirin for primary prevention of cardiovascular events in people with diabetes: metaanalysis of randomised controlled trials. BMJ 2009;339:b4531.

37 Strazzullo P, D’Elia L, Kandala NB, Cappuccio FP: Salt intake, stroke, and cardiovascular disease: meta-analysis of prospective studies. BMJ 2009;339:b4567.

38 Jamrozik K, Broadhurst RJ, Anderson CS, Stewart-Wynne EG: The role of lifestyle factors in the etiology of stroke. A populationbased case-control study in Perth, Western Australia. Stroke 1994;25:51-59.

39 He FJ, MacGregor GA: Salt reduction lowers cardiovascular risk: meta-analysis of outcome trials. Lancet 2011;378:380-382.

40 Frohlich ED: The salt conundrum: a hypoth esis. Hypertension 2007;50:161-166. reduction on blood pressure: a meta-analysis of randomized trials. Implications for public health. J Hum Hypertens 2002;16: 761-770.

42 Pimenta E, Gaddam KK, Oparil S, Aban I, Husain S, Dell'Italia LJ, Calhoun DA: Effects of dietary sodium reduction on blood pressure in subjects with resistant hypertension: results from a randomized trial. Hypertension 2009;54:475-481.

43 Clarke R, Halsey J, Lewington S, Lonn E, Armitage J, Manson JE, Bonaa KH, Spence JD, Nygard O, Jamison R, et al: Effects of lowering homocysteine levels with B vitamins on cardiovascular disease, cancer, and cause-specific mortality: meta-analysis of 8 randomized trials involving 37485 individuals. Arch Intern Med 2010;170:1622-1631.

-44 Boden WE, Probstfield JL, Anderson T, Chaitman BR, Desvignes-Nickens P, Koprowicz K, McBride R, Teo K, Weintraub W: Niacin in patients with low HDL cholesterol levels receiving intensive statin therapy. $\mathrm{N}$ Engl J Med 2011;365:2255-2267.

45 D’Elia L, Barba G, Cappuccio FP, Strazzullo P: Potassium intake, stroke, and cardiovascular disease a meta-analysis of prospective studies. J Am Coll Cardiol 2011;57:1210-1219.
41 He FJ, MacGregor GA: Effect of modest salt
46 Larsson SC, Orsini N, Wolk A: Dietary potassium intake and risk of stroke: a dose-response meta-analysis of prospective studies. Stroke 2011;42:2746-2750.

47 Dickinson HO, Nicolson DJ, Campbell F, Beyer FR, Mason J: Potassium supplementation for the management of primary hypertension in adults. Cochrane Database Syst Rev 2006;CD004641.

48 Bolland MJ, Avenell A, Baron JA, Grey A, MacLennan GS, Gamble GD, Reid IR: Effect of calcium supplements on risk of myocardial infarction and cardiovascular events: metaanalysis. BMJ 2010;341:c3691.

49 Bolland MJ, Grey A, Avenell A, Gamble GD, Reid IR: Calcium supplements with or without vitamin $\mathrm{D}$ and risk of cardiovascular events: reanalysis of the Women's Health Initiative limited access dataset and meta-analysis. BMJ 2011;342:d2040.

$50 \mathrm{He}$ K, Merchant A, Rimm EB, Rosner BA, Stampfer MJ, Willett WC, Ascherio A: Dietary fat intake and risk of stroke in male US healthcare professionals: 14 year prospective cohort study. BMJ 2003;327:777-782.

51 Howard BV, Van Horn L, Hsia J, Manson JE, Stefanick ML, Wassertheil-Smoller S, Kuller LH, LaCroix AZ, Langer RD, Lasser NL, et al: Low-fat dietary pattern and risk of cardiovascular disease: the Women's Health Initiative Randomized Controlled Dietary Modification Trial. JAMA 2006;295:655-666.

52 Mozaffarian D, Aro A, Willett WC: Health effects of trans-fatty acids: experimental and observational evidence. Eur J Clin Nutr 2009; 63(suppl 2):S5-S21.

53 Mozaffarian D, Micha R, Wallace S: Effects on coronary heart disease of increasing polyunsaturated fat in place of saturated fat: a systematic review and meta-analysis of randomized controlled trials. PLoS Med 2010; 7:e1000252.

54 Marik PE, Varon J: Omega-3 dietary supplements and the risk of cardiovascular events: a systematic review. Clin Cardiol 2009;32:365372.

55 Galan P, Kesse-Guyot E, Czernichow S, Briancon S, Blacher J, Hercberg S: Effects of B vitamins and omega 3 fatty acids on cardiovascular diseases: a randomised placebo controlled trial. BMJ 2010;341:c6273.

56 de Goede J, Verschuren WM, Boer JM, Kromhout D, Geleijnse JM: Alpha-linolenic acid intake and 10-year incidence of coronary heart disease and stroke in 20,000 middle-aged men and women in the Netherlands. PLoS One 2011;6:e17967.

57 Preis SR, Stampfer MJ, Spiegelman D, Willett WC, Rimm EB: Lack of association between dietary protein intake and risk of stroke among middle-aged men. Am J Clin Nutr 2010;91:39-45.

58 Livesey G, Taylor R, Hulshof T, Howlett J: Glycemic response and health - a systematic review and meta-analysis: relations between dietary glycemic properties and health outcomes. Am J Clin Nutr 2008;87:258S-268S. 
59 Oba S, Nagata C, Nakamura K, Fujii K, Kawachi T, Takatsuka N, Shimizu H: Dietary glycemic index, glycemic load, and intake of carbohydrate and rice in relation to risk of mortality from stroke and its subtypes in Japanese men and women. Metabolism 2010;59:15741582.

60 Larsson SC, Orsini N: Fish consumption and the risk of stroke: a dose-response meta-analysis. Stroke 2011;42:3621-3623.

61 Micha R, Wallace SK, Mozaffarian D: Red and processed meat consumption and risk of incident coronary heart disease, stroke, and diabetes mellitus: a systematic review and metaanalysis. Circulation 2010;121:2271-2283.
62 He FJ, Nowson CA, MacGregor GA: Fruit and vegetable consumption and stroke: metaanalysis of cohort studies. Lancet 2006;367: 320-326.

63 Karppi J, Laukkanen JA, Sivenius J, Ronkainen K, Kurl S: Serum lycopene decreases the risk of stroke in men: a population-based follow-up study. Neurology 2012;79:1540-1547.

64 Larsson SC, Orsini N: Coffee consumption and risk of stroke: a dose-response meta-analysis of prospective studies. Am J Epidemiol 2011;174:993-1001.

65 Arab L, Liu W, Elashoff D: Green and black tea consumption and risk of stroke: a metaanalysis. Stroke 2009;40:1786-1792.
66 Buitrago-Lopez A, Sanderson J, Johnson L, Warnakula S, Wood A, Di Angelantonio E, Franco OH: Chocolate consumption and cardiometabolic disorders: systematic review and meta-analysis. BMJ 2011;343:d4488.

67 Estruch R, Ros E, Salas-Salvado J, Covas MI, Corella D, Aros F, Gomez-Gracia E, RuizGutierrez V, Fiol M, et al: Primary prevention of cardiovascular disease with a Mediterranean diet. N Engl J Med 2013;368:12791290.

68 Chiuve SE, Rexrode KM, Spiegelman D, Logroscino G, Manson JE, Rimm EB: Primary prevention of stroke by healthy lifestyle. Circulation 2008;118:947-954. 